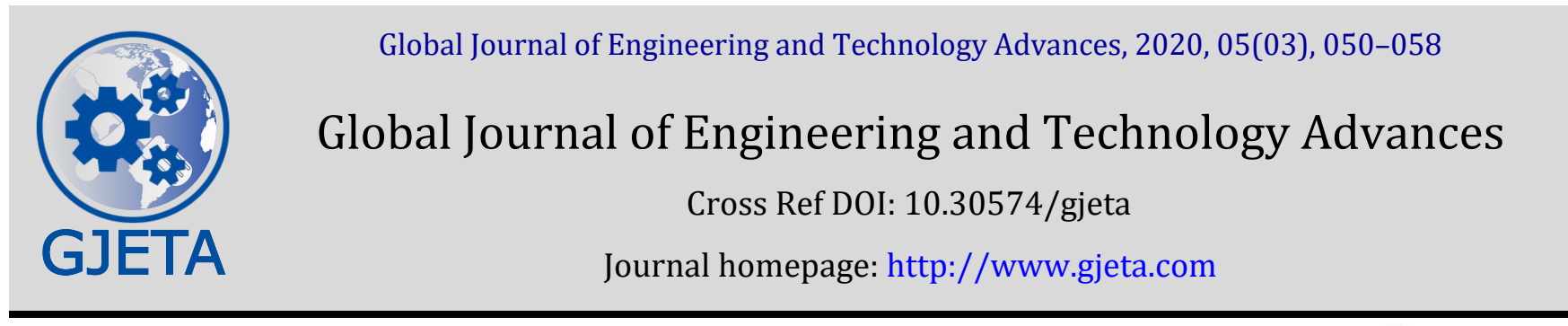

(RESEARCH ARTICLE)

\title{
Research results on the effects of magnetic fields on crude oil
}

\author{
Nora Mamulaishvili ${ }^{1,}{ }^{*}$, Gaioz Partskhaladze ${ }^{1}$, Gocha Chavleshvili ${ }^{1}$, Otar Janelidze ${ }^{1}$ and Nigar Salimova ${ }^{2}$ \\ 1 Technical faculty, Batumi Shota Rustaveli State Univefsity, Georgia. \\ 2 Department of Petroleum chemistry, Oil Academy of Azerbaijan. Baki, Azerbaijan.
}

Publication history: Received on 03 December 2020; revised on 11 December 2020; accepted on 13 December 2020

Article DOI: https://doi.org/10.30574/gjeta.2020.5.3.0108

\begin{abstract}
The paper presents the results of the process of demulsification of crude oil, well No. 15 of the Supsa field. The reasons for the formation of persistent petroleum emulsion are considered, the component composition of crude oil is determined, including the content of the amount of formation water. The experiments were carried out at low (20$30) \mathrm{Hz}$ and high (50-80) Hz frequencies of the magnetic field. The destruction of the oil-water emulsion was carried out without heat treatment under conditions of stabilization of the magnetic field and demulsifier Alkan 202. The technological scheme and parameters of crude oil dehydration are given. The influence of the magnetic field on the rate of destruction of the water-oil emulsion and the amount of released water is shown.
\end{abstract}

Keywords: Crude oil; Water; Supsa; Stable emulsion; Separation; Alkan De 202; Magnetic solenoid.

\section{Introduction}

Removal of water contained in crude oil is rather difficult due to the formation of a stable water-in-oil emulsion with a high content of heavy oil components. The high content of asphaltenes and resins in reservoir oil contributes to the formation of stable oil-water emulsions. Asphaltenes are considered to have the highest stability in a water-in-oil emul $\neg$ sion because they contain aromatic and polycyclic aromatic hydrocarbons. The stability of an oil-water emulsion depends on its viscosity. Unlike paraffins, with a high content of asphaltenes in oil, the viscosity increases accordingly. $[1],[2]$;

The stability of a stable water-oil emulsion depends:

- From the $\%$ asphaltene content, it was found that at a 30\% asphaltene content, the stability of the emulsion increases. A further increase in the concentration of asphaltenes leads to a decrease in the stability of the emulsion.

- Mechanical impurities with a size of $0.75 \mathrm{~mm}$ in the bottomhole zone of the oil reservoir,, has a positive effect on the stability of the emulsion.

- $\quad$ The stability of the emulsion also depends on the salinity and $\mathrm{pH}$ of the formation water.

It was found that with an increase in the mineralization of formation water, the stability of the emulsion increases. At $\mathrm{pH}=1.3$ and $\mathrm{pH}=12.9$, very stable emulsions are formed, and at $\mathrm{pH}=6-9$, the stability of the emulsion decreases. [3], $[4],[5]$;

Based on the tasks set, the article [6] presents the results of studies of the effect of a low-frequency alternating magnetic field with a frequency of 20, 25 and $30 \mathrm{~Hz}$ in combination with demulsifiers (Reapon-4V, INTEX-720, SNPKh-4315D) on

${ }^{*}$ Corresponding author: N. Mamulaishvili

Batumi Shota Rustaveli State Univefsity, Georgia ntry.

Copyright (C) 2020 Author(s) retain the copyright of this article. This article is published under the terms of the Creative Commons Attribution Liscense 4.0. 
demulsification natural and artificial oil-water emulsions of oil from the Kiengop field. impact. The use of this method makes it possible to intensify the demulsification process, reduce its temperature to $30^{\circ} \mathrm{C}$, increase the volume of separated water and the depth of oil dehydration in comparison with traditional thermochemical dehydration. [6] [7]

This article discusses the reasons for the formation of a stable oil emulsion during oil production from the Supsa field. Industrial demulsifiers are considered, the efficiency of destruction of oil emulsion using solutions of nonionic surfactants is shown. The results of the process of dehydration of crude oil with the use of nonionic demulsifier "ALKAN DE 202" are presented. The physicochemical parameters of crude oil, density, surface tension, demulsifier efficiency, and the amount of released water in the original and in the dehydrated product have been determined [8],

In order to substantiate the nature of surfactant behavior, we have previously investigated the wetting properties of aqueous solutions of the investigated agents on the hydrophobic surface of an oil reservoir [9]. We used Sulfanol (anionic surfactant) and Alcan 202 (nonionic surfactant) with an industrial production base. As a result of the injection of aqueous surfactant solutions into the formation, the surface-molecular properties of the medium change, namely, the surface tension at the boundary between oil and mountain steam, the wetting of the surface of the formation fluid is improved, and the intensity of capillary feeding of rocks increases. [9]

\section{Material and methods}

Destruction of water-oil emulsion is possible by traditional methods: Gravitational, Magnetic and of thermo chemical method.

The proposed technological scheme provides for the destruction of the oil emulsion under the action of a low-frequency magnetic field using a solenoid and a demulsifier

Method 1. The method consisted in carrying out the demulsification process using a magnetic solenoid. The solenoid core was made of $140 \mathrm{~mm}$ long ferrite. Diameter $8 \mathrm{~mm}$. Twisted from above with a copper conductor.

Method 2. This method involves processing samples at higher magnetic field frequencies. of the magnetic field in the range of 50-80 hertz

Most demulsifiers are very expensive, and we chose ALKAN 202 as a demulsifier. Demulsifier "ALKAN-202" is intended for preparation of crude oil to refining in dehydrating, desalting and removing of mechanical admixtures at oil production. By its qualitative and operating characteristics "ALKAN-202" satisfies the international requirements and belongs to the best world standards, provides complete and fast separation of water and salts, clear separation of phases, increasing of production reliability and improvement of ecology [10].

Together with an oil company, BP, various demulsifiers were tested at the Sangachal terminal, where the water content in the oil was only $0.8-1.5 \%$. It was necessary to bring this oil to the first quality category, that is, the water content should not exceed $0.5 \%$. It should be noted that oil containing less than $5 \%$ water is very difficult to process. When the crude oil was treated with the HTO Alkan Ltd reagent, the residual water content was less than $0.2 \%$, and the phase separation was so clear that no traces of oil were observed in the separated water.

The demulsifier was delivered on the basis of friendly cooperation between AGNA and BSU.

To determine the physical parameters of reservoir oil wells. No. 15 of the Supsa field, standard methods of testing petroleum and petroleum products were applied.

The water content in the crude and dehydrated oil sample was determined by distillation on a Dean and Stark apparatus in accordance with GOST 2477-2014.

The experiments were carried out in the oil and gas training laboratory of the Faculty of Technology of Batumi State

\section{Results}

\subsection{Characterization of crude oil from the Supsa field}

Oil-water emulsion was picked up from well \# 15. The Supsa field, which was discovered in 1889 by the Anglo-Belgiskiy oil companies. The depth of the well is $779 \mathrm{~m}$. Production at this stage occurs periodically with the use of a sucker rod pump (rocker).At this stagewell productivity is 300 liters / hour.

In the table 1 given real data Oil producing parameters of well No. 15 of Supsa field 
Table 1 Oil producing parameters of well No. 15 of Supsa field

\begin{tabular}{|c|c|c|c|c|c|c|c|c|}
\hline \multirow{2}{*}{$\begin{array}{l}\text { Well } \\
\text { № }\end{array}$} & \multirow{2}{*}{$\begin{array}{l}\text { Mining } \\
\text { method }\end{array}$} & \multicolumn{3}{|c|}{ T / month } & \multicolumn{2}{|c|}{$T /$ day } & \multirow{2}{*}{$\begin{array}{l}\text { Water } \\
\%\end{array}$} & \multirow{2}{*}{$\begin{array}{l}\text { Gas factor } \\
\%\end{array}$} \\
\hline & & $\begin{array}{l}\text { Petrol } \\
\text { eum }\end{array}$ & water & gas & $\begin{array}{l}\text { Petrol } \\
\text { eum }\end{array}$ & fluid & & \\
\hline 14 & \multirow{3}{*}{$\begin{array}{l}\text { pump } \\
\text { rocking }\end{array}$} & 7,98 & 62,808 & 0,239 & 0,26 & 0,4 & 34 & 30 \\
\hline 15 & & 4,587 & 35,944 & 0,138 & 0,15 & 0,25 & 36 & 30 \\
\hline 34 & & 1,323 & 16,912 & 0,04 & 0,04 & 0,12 & 60 & 30 \\
\hline
\end{tabular}

Table 2 Physical parameters of reservoir oil of well No. 15 of Supsa field

\begin{tabular}{|l|l|l|l|}
\hline & Name of parameters & value & Test method \\
\hline 1 & Density 200C, g / cm3 & $0.8788-0.8864$ & Tu GOST 3900-85 \\
\hline 2 & Kinematic viscosity 200C, mm2 / s & $11.874-15.85$ & Tu GOST 33-2000 \\
\hline 3 & Mass fraction of water\% & $32-34$ & Tu GOST 2477-65 \\
\hline 4 & Mass fraction of solids\% mass fractio & $0.015-0.021$ & TuGOST 6370- -83 \\
\hline 5 & asphaltens \% & 7.74 & TuGOST 11851-85 \\
\hline 6 & resins \% & 29.3 & TuGOST 11851-85 \\
\hline 7 & paraffins \% & 3.9 & TuGOST 11851-85 \\
\hline 8 & sulfur compounds \% & 0.44 & Tu GOST 1437-75 \\
\hline
\end{tabular}

Heavy (density over $0.8864 \mathrm{~g} / \mathrm{cm} 3$ ), highly viscous (kinematic viscosity at 200C $-15.85 \mathrm{~mm} 2$ / s.) And low-paraffinic (3.9\%). resinous (from 22 to $29 \%$ ) with a high content of asphaltenes (more than 7.74\%) (tables 1-2). Produced water is hydro carbonate. Total mineralization $24.1 \mathrm{~g} / \mathrm{l}$

Specific gravity $(1.006-1.015) \mathrm{g} / \mathrm{cm} 3, \mathrm{PH}=8.0$ : The result of the study shows that a stable water-oil emulsion is obtained due to the high content of resins and asphaltenes in the oil of the Supsa field.

Marketable oil, according to the degree of preparation, must comply with the state standard groups (Table 3)

Table 3 According to the degree of preparation, oil is divided into groups ГОСТ Р 51858-200.

\begin{tabular}{|c|c|c|c|c|}
\hline \multirow[t]{2}{*}{ Indicator name Norm } & \multicolumn{3}{|c|}{ for group oil } & \multirow[t]{2}{*}{ Test method } \\
\hline & 1 & 2 & 3 & \\
\hline 1 Mass fraction of water, $\%$, no more & 0,5 & 0,5 & 1,0 & Tu GOST 2477 и 9.5 \\
\hline 2 Mass concentration of chloride salts, $\mathrm{mg} / \mathrm{dm}^{3}$, no more & 100 & 300 & 900 & Tu GOST 21534 и 9.6 \\
\hline 3 Mass fraction of mechanical impurities, $\%$, no more & \multicolumn{3}{|c|}{0,05} & Tu GOST 6370 \\
\hline 4 Saturated vapor pressure, $\mathrm{kPa}(\mathrm{mm} \mathrm{Hg})$, no more & \multicolumn{3}{|c|}{$66,7(500)$} & Tu GOST 1756, \\
\hline $\begin{array}{l}5 \text { Mass fraction of organic chlorides in the fraction } \\
\text { boiling up to } 2040 \mathrm{C}, \mathrm{ppm}(\mathrm{ppm}) \text {, no more }\end{array}$ & 10 & 10 & 10 & Tu GOST P 52247 \\
\hline
\end{tabular}




\subsection{Materials and equipment}

Samples were taken in standard $100 \mathrm{ml}$ cylinders. Each sample contained a certain amount of demulsifier (from 0.01 to 1.0). The demulsification process was carried out at $\mathrm{T}=20-22{ }^{\circ} \mathrm{C}$ for30-60 minutes. After that, two phases were separated: upper oil and lower water. [8], [11],[12].

The results of research given (table 4).

Table 4 The research results Supsa oil emulsion field $\left(22^{\circ} \mathrm{C}\right)$.

\begin{tabular}{|l|l|l|l|l|l|}
\hline No & $\begin{array}{l}\text { Quantity } \\
\text { added Alkan }-\end{array}$ & $\begin{array}{l}\text { Surffcetension } \\
\mathbf{n} \text { (202 } \mathbf{~ m l}\end{array}$ & $\begin{array}{l}\text { SeparationWater. } \\
\text { of the AlkanDE- } \\
\mathbf{2 0 2} \mathbf{~ m l}\end{array}$ & $\begin{array}{l}\text { Efficiency of } \\
\text { the demulsifier } \\
\text { AlkanDE-202 } \\
\text { \% }\end{array}$ & $\begin{array}{l}\text { Efficiencyof the } \\
\text { demulsifierDisolvan \% }\end{array}$ \\
\hline 1 & 0.005 & 72 & 21 & 70 & 60 \\
\hline 2 & 0.010 & 74 & 25 & 73 & 70 \\
\hline 3 & 0.025 & 76 & 27.5 & 91 & 85 \\
\hline 4 & 0.05 & 80 & 28.5 & 95 & 90 \\
\hline 5 & 0.075 & 75 & 26.5. & 88 & 94 \\
\hline 6 & 0.1 & 70 & 26.0 & 86 & 98 \\
\hline
\end{tabular}

From table 3 the optimal mode of the demulsification process, the consumption of the demulsifier is established. Significant superiority of the test reagent with Disolvan is shown.

In order to identify real results, we determined the coefficient of water separation (degree of demulsification) for the processes of demulsification 0/W Emulsions

Based on the laboratory tests carried out, it was revealed:

Oil from the Supsa field, in terms of its physicochemical properties, is classified as [8]

Efficiency of the demulgator calculate:

$\mathrm{E}=\mathrm{V} / \mathrm{V}_{0} \cdot 100 \%$

Where:

$\mathrm{V}$ - Released water in graduated cylinders in $\mathrm{ml}$.

$\mathrm{V}_{0}$ is the initial water content of the $\mathrm{B} / \mathrm{H}$ emulsion in $\mathrm{ml}$;

E- Emulsification coefficient \% [8]

In order to reduce the dosage of the demulsifier and also to reduce the settling time of the emulsion, we tested the demulsification process in the aggregate of the demulsifier and the magnic field. The experiments were carried out separately according to method 1 and method 2 .

Method 1. The method consisted in carrying out the demulsification process using a magnetic solenoid.

In the samples under study, a low-frequency current in the range of 20-50 hertz was passed through the solenoid and was observed during the separation of water. See photo 1.

Samples were prepared in graduated cylinders with a volume of 100-250 ml each. Then, a certain amount of demulsifier (0.5-1.0 ml) was introduced into each sample at $\mathrm{T}=20-22^{\circ} \mathrm{C}$. Then the low-frequency current was suppressed in the range of 20-40 hertz. As a result, two separate phases were formed: an upper oil phase and a lower water phase. fig. 4 The process of settling, while the optimal level is preliminarily determined, which allows to achieve the minimum proportion of water in oil, and the settling of the emulsion is carried out during processing by a magnetic field. EFFECT: method makes it possible to reduce settling time and capital costs for oil dehydration by 2-4 times. The water content in the samples was determined by the Dean-Stark distillation method. The results obtained are shown in table 5 and Fig.1.Fig.2. 


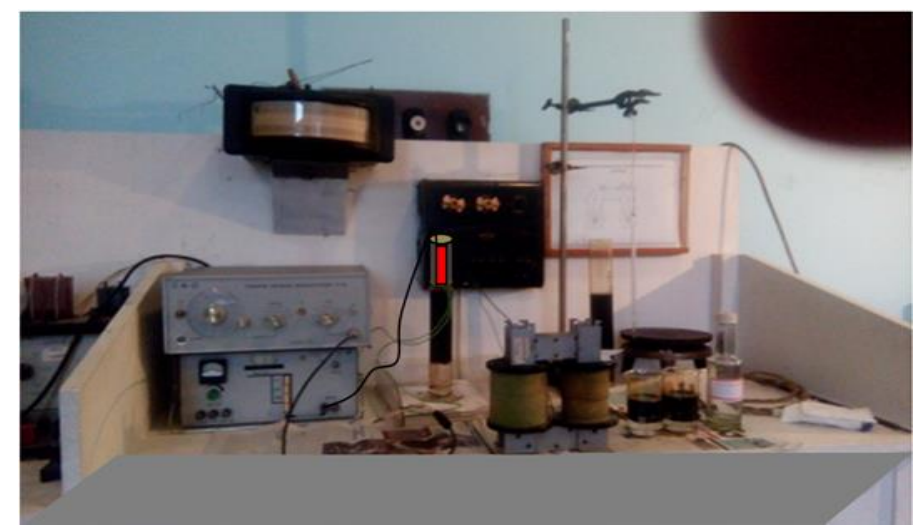

Photo 1 Demulsification of oil emulsion when exposed to a magnetic fieldin the range of 20-50 hertz, in the presence of demulsifie rAlkan - 202. Method 1.

(BSU Technological Faculty, in petroleum research laboratory conditions)

Table 5 Technological parameters of the dehydration process in W / oil

\begin{tabular}{|l|l|l|l|l|l|l|l|l|l|l|}
\hline \multicolumn{1}{|c|}{ Name parameters } & \multicolumn{6}{l}{$\begin{array}{l}\text { The value of the indicators at the optimal frequency of the } \\
\text { magnetic field 30 hertz }\end{array}$} \\
\hline 1. Processing and settling time min. & 0 & 10 & 20 & 30 & 40 & 50 & 60 & 70 & 80 & 90 \\
\hline 2. content of water in oilatdemulsifier \% & 30 & 20 & 12 & 8 & 6 & 5 & 4 & 2.0 & 1.0 & \\
\hline $\begin{array}{l}\text { 3.the water content in the oil by the action of } \\
\text { a solenoid and a demulsifier. \% }\end{array}$ & 30 & 15 & 10 & 5 & 4 & 3 & 2.0 & 1.5 & 0.5 & \\
\hline $\begin{array}{l}\text { 4. the amount of water released at the } \\
\text { demulsifier \%. }\end{array}$ & 20 & 40 & 60 & 70 & 75 & 80 & 85 & 90 & \\
\hline $\begin{array}{l}\text { 5.the amount of released water at the } \\
\text { demulsifier and solenoid. \%. }\end{array}$ & 0 & 50 & 70 & 80 & 85 & 90 & 90 & 95 & & \\
\hline
\end{tabular}

As can be seen from the table, the water content in \% in oil samples when using only a demulsifier is much higher than in the samples, a solenoid with the addition of a demulsifier Fig. 1

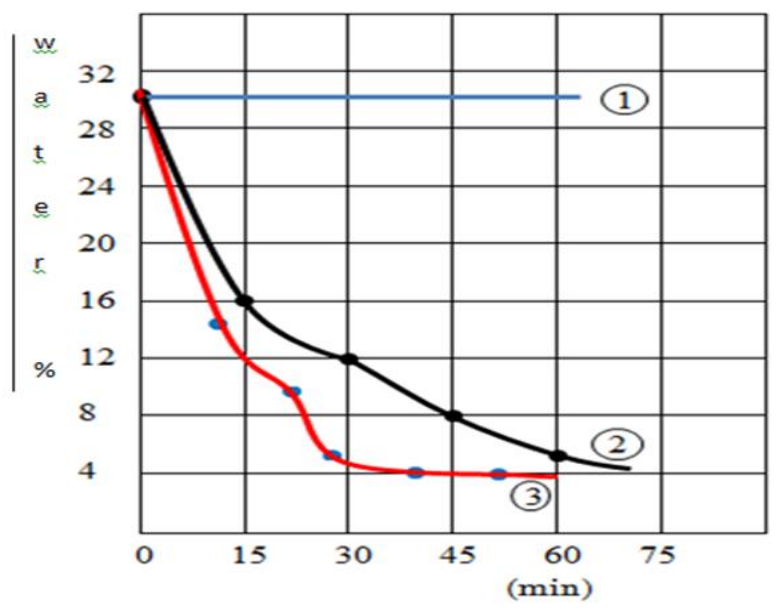

Figure 1 water content in the emulsion samples

1 -The sample is empty; 2- Sample with demulsifier; 3 - Sample with demulsifier and solenoid 
As seen from Fig. 2. The amount of residual water in oil samples with a demulsifier is greater than in oil samples with a solenoid in the presence of a demulsifier position (3)

The greatest amount of seen water in $\%$ is observed in sample 3 where in 60 minutes it reaches $90 \%$, in sample 2 the amount of released water reaches $80 \%$.

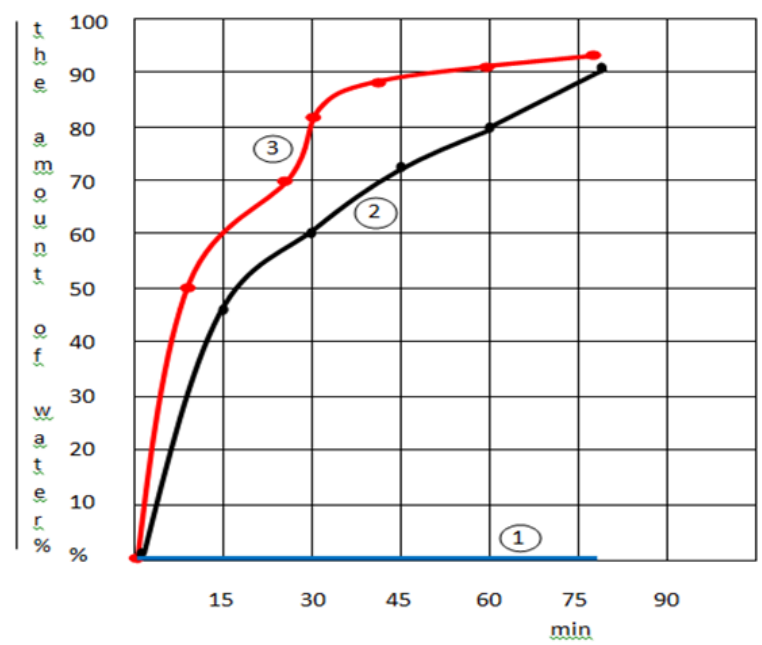

Figure 2 Dependence of the amount of separated water on time.

1 - The sample is empty; 2 - Sample with demulsifier; 3 -Test with demulsifier and solenoid;

Method 2. This method involves processing samples at higher magnetic field frequencies. Graduated cylinders with the test solution were placed in a coil and a voltage of 150-180 volts was applied. The frequency of the magnetic field varied from 20 to 80 hertz. Photo 2.

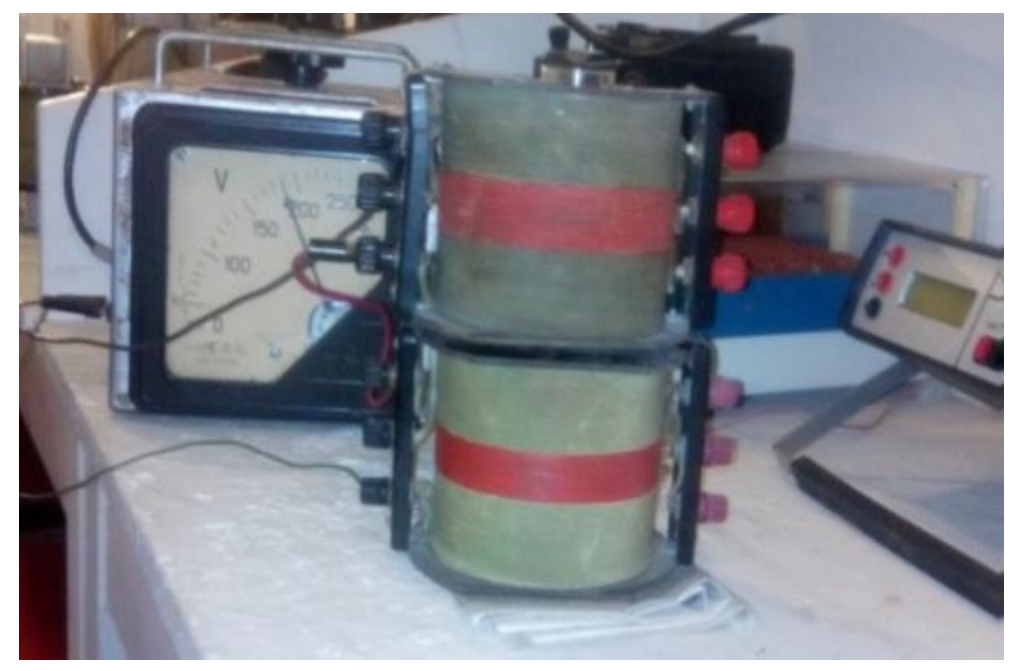

Photo 2 Dehydration emulsion under conditions of high-frequency magnetic field BSU Technological Faculty, in petroleum research laboratory conditions.

An increase in the frequencies of the magnetic field in the range of 50-80 hertz did not lead to an increase in the rate of demulsification.

On the basis of the tests carried out by us, we have developed a technological compression of demulsification specifically for oil from the Supsa field. 


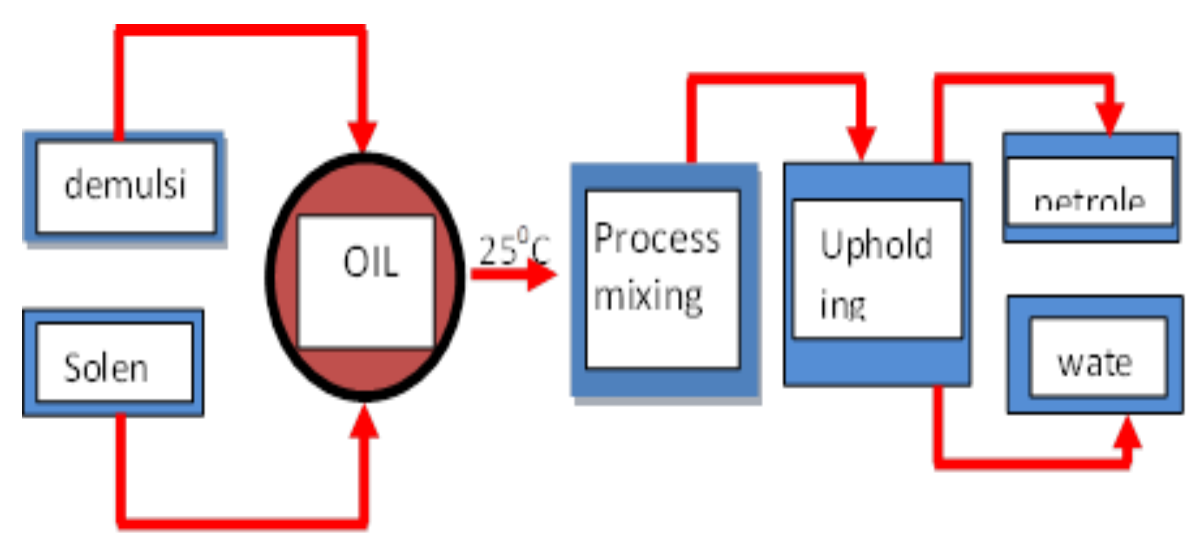

Figure 3 Technological ofdemulsification specifically for oil from the Supsa field. BSU Technological Faculty, in petroleum research laboratory conditions.

The technological scheme of crude oil demulsification is preset by the action of a low-frequency magnetic field (30 hertz) in the presence of a demulsifier, Alkan de 202, without thermal heating. Below is the process mode for the demulsification of crude oil from the Supsa fie.

Table 6 Technological parameters for demulsification of the test oil.

\begin{tabular}{|l|l|l|l|l|l|l|l|l|l|}
\hline No & $\begin{array}{l}\text { A place } \\
\text { Christ } \\
\text { masnie } \\
\text { oil }\end{array}$ & $\begin{array}{l}\text { Demul } \\
\text { sifier } \\
\text { name }\end{array}$ & $\begin{array}{l}\text { Numb } \\
\text { er of } \\
\text { emulsi } \\
\text { ons } \\
\text { tone }\end{array}$ & $\begin{array}{l}\text { Amount } \\
\text { of } \\
\text { Water } \\
\text { the } \\
\text { emulsio } \\
\text { n \% }\end{array}$ & $\begin{array}{l}\text { Temper } \\
\text { ature } \\
\text { heating } \\
\mathbf{2 0} \text { C }\end{array}$ & $\begin{array}{l}\text { Dela } \\
\text { minati } \\
\text { on } \\
\text { Time } \\
\text { hour }\end{array}$ & $\begin{array}{l}\text { Quanti } \\
\text { ty of } \\
\text { olL } \\
\text { tone }\end{array}$ & $\begin{array}{l}\text { Consumpti } \\
\text { on gemul } \\
\text { gator } \\
\text { g/tone }\end{array}$ & $\begin{array}{l}\text { Residu } \\
\text { al Wa } \\
\text { ter } \\
\text { Amoun } \\
\text { t \%o }\end{array}$ \\
\hline 1 & $\begin{array}{l}\text { Bulla } \\
\text { denise } \\
\text { (Azerb.) }\end{array}$ & $\begin{array}{l}\text { Alkan } \\
\text { De 202 }\end{array}$ & 6591 & 40 & 52 & 4 & 3955 & 110 & 0.32 \\
\hline 2 & $\begin{array}{l}\text { Bulla } \\
\text { denise } \\
\text { (Azerb.) }\end{array}$ & $\begin{array}{l}\text { Separol } \\
3337\end{array}$ & 5150 & 40 & 53 & 4 & 3996 & 130 & 0.2 \\
\hline 3 & $\begin{array}{l}\text { Bulla } \\
\text { denise } \\
\text { (Azerb.) }\end{array}$ & $\begin{array}{l}\text { Disolvan } \\
4411\end{array}$ & 4620 & 40 & 53 & 4 & 2772 & 130 & 0.2 \\
\hline 4 & $\begin{array}{l}\text { Supsa } \\
\text { (Georgia }\end{array}$ & $\begin{array}{l}\text { Alkan } \\
\text { De 202 }\end{array}$ & 47455 & 32 & $22-25$ & $1-2$ & 9965 & 110 & 0.9 \\
\hline 5 & $\begin{array}{l}\text { Supsa } \\
\text { (Georgia }\end{array}$ & $\begin{array}{l}\text { Alkan } \\
\text { De 202 } \\
\text { In } \\
\text { presence of } \\
\text { Solenoid }\end{array}$ & 47455 & 32 & $22-25$ & 90 & 9965 & 110 & 0.5 \\
\hline
\end{tabular}




\section{Discussion}

Based on the studies reviewed, it was revealed: The importance of the demulsifier,as well as the advantage and costeffectiveness of the method used in comparison with other demulsification methods. It is convincing that the process of demulsification of an oil-water emulsion under the action of a magnetic field and ultrasound effectively proceeds in the presence of a demulsifier, and in its absence, the process stops.

In addition, when demulsifying oil by the ultrasonic method, high frequencies (20 kg) of energy are required, and the consumption of demulsifier is $250 \mathrm{mg}$ per liter [13]

The superiority of the test reagent with disolvan is shown.

The optimal mode of the demulsification process and the consumption of the demulsifier have been established. A significant superiority of the test reagent with disolvan was shown.

As can be seen from the table, the water content in oil samples when using only a demulsifier is much higher than in samples of the solenoid with the addition of a demulsifier. Figure: 1

Accordingly, the amount of water released in oil samples with a demulsifier is less than in oil samples with a solenoid with the addition of a demulsifier. Figure: 2

\section{Conclusion}

- The technological scheme is presented and the technological parameters of the demulsification process of the oil emulsion of the Supsa field are determined.

- It was revealed that the formation of stable oil emulsions is associated with a high content of asphaltenes and resins in the oil of the Supsa field.

- It is shown that a low-frequency magnetic field significantly increases the rate of separation of an oil-water emulsion in the presence of a demulsifier Alkan 202.

- It is shown that the process of demulsification of the oil emulsion occurs instantly at the initial stage of the process within 15-20 minutes at a magnetic field frequency of $30 \mathrm{~Hz}$.

\section{Compliance with ethical standards}

\section{Acknowledgments}

The presented work was created on the basis of technological faculty o BSU in the laboratory of oil and gas technology. Unforgettable help was provided by the engineer geologist (Supsa field) Archil Lominadze. Personally, I and all coauthors will blog for his professional knowledge and services.

\section{Disclosure of conflict of interest}

All authors declare no conflict of interest is exist.

\section{References}

[1] Murtada Mohammed Abdulredha, Siti Aslina, Hussain Luqman. Chuah Abdullah Overview on petroleum emulsions, formation, influence and demulsification treatment techniques. Arabian Journal of Chemistry . Elsevier . January 2020; 13(1): 3403-3428.

[2] Merv fingas ben fieldhouse. Investigation of the process of formation of emulsions such as water in oil. Marine Pollution Bulletin - Journal - Elsevier. September - December 2003; 47(9-12); 369-396.

[3] Tsiganov Dmitry Genadievych Composite formulations for the preparation of stable field emulsions. Composite formulations for the preparation processes of sustainable

[4] B Borges, M Rondon, O Sereno, H Asuahe. Breakdown of water-in-crude oil emulsions. 3. Influence of mineralization and water-oil composition on the action of the demulsifier. Energy Fuels. 2009; 23(3): 1568-1574.

[5] De Oliveira et al. MCK de Oliveira, LR Miranda, AB de Carvalho, DFS Miranda Viscosity of water-in-oil emulsions from various Brazilian crude oils of the American Petroleum Institute. Energy Fuels. 2018; 32(3): 2749 - 2759. 
[6] Shaikhulov AM, Bojchuk AA, Dokichev VA, Svirsky SE, Singizova VH, Kresteleva IV, Telin AG. Magnetikfield effect on demulsificationof water -in-oil emulsion of Kiengorskoefield a4 formation. j. Oil and gas business. 2014, t. 12, No. 1.

[7] New Insights into the Application of a Magnetic Field to Enhance Oil Recovery from Oil-Wet Carbonate Reservoirs. Journal: Energy \& Fuels. 1 November 2019.

[8] Mamulaishvili N, Khitarishvili T, Partskhaladze G, Chavleshvili G, Zoidze R.. Supsa Crude Oil DemulsificationTechnologyDevelopment by Usingnon-ionogenic Surfactant Solution.International Journal of EngineeringInnovation\& Research. 2017; 6(6): 2277- 5668.

[9] Mamulaishvili ND, Salimova NA, Khitarishvili TD, Baladze DA. Effect of various classes SAS onhydrophobic surface of oil stratum.The "International journal of Appled and fundamental research" №2, 15-21.11.2014 Munch. Germany.

[10] http://alkan-sts.com/?s=

[11] N Mamulaishvili, G Partskhaladze, G Chavleshvili , O Janelidze. Batumi ShotaRustaveli State University, Georgia F6 (71): The Effect of Magnetic Field on the Destruction Petroleum Emulsion 11-th Japanese-Mediterranean Workshop on Applied Electromagnetic Engineering for Magnetic, Superconducting, Multifunctional and Nanomaterials Batumi ShotaRustaveli State University July, 16-19, 2019, Batumi, Georgia. Patent 2,067,492 Metod of oil dehidration.

[12] Mamulaishvili N, Salimova N, Khitarishviliand T, Partskhaladze G. Regulation of filtration and reservoirfeatures of oil stratum rock withuse of compositesolutions of SAS.DOI:10.4172/2157-7463-C1-041;3rdWorld Congress onPetroleum Engineering and Natural Gas Recovery. July20-21, 2018. Sydney, Australia.

[13] Mingxu Yi, Jun Huang,Lifeng Wang.Research on Crude Oil Demulsification Using the Combined Method of Ultrasound and Chemical Demulsifier J. Chemistry. Volume 2017 https://doi.org/10.1155/2017/9147926 